\title{
E-READINESS DALAM PENERAPAN E-PLANNING DI KABUPATEN MAMBERAMO TENGAH PROVINSI PAPUA
}

\author{
Oleh \\ Nesty Epa ${ }^{1}$, \\ Sampara Lukman ${ }^{2}$, Ella Wargadinata ${ }^{3}$ \\ 1) Pemerintah Kabupaten Mamberamo Tengah \\ ) Program Magister Terapan Studi Pemerintahan Daerah Institut Pemerintahan Dalam Negeri \\ ria_epa@yahoo.com \\ 2,3) Institut Pemerintahan Dalam Negeri
}

\begin{abstract}
$T_{i}^{i}$ he purpose of this research is to see the E-Readiness Mamberamo Tengah District in mplementing E-Planning. Geographically, Mamberamo Tengah district has limited access but it is required to progress as any other districts in Indonesia. This research will elaborate on any exisiting condition and requirements that need to be fulfilled by Mamberamo Tengah District to implement E-planning.

This is a qualitative research. Method used in measuring e-readiness is e-readiness method developed from variable relationship by Musa (2010). Indicators that is included into the measurement tool of e-readiness framework contain of three factors which is technology, human resources and institutional factors particularly at the local level (regional government).

The result of this e-readiness measurement showcased the unpreparedness of Mamberamo Tengah district to implement e-planning whether by looking at the technology, human resources or institutional side. Therefore it should become government's attention to develop needed infrastructure, build cooperation between government, private sector and the community and last but not least develop specific regulation on Regional Planning Information System/Sistem Informasi Perencanaan Daerah (SIPD) so that in the future the E-Planning can be implemented more effectively and efficiently based on the regulation.
\end{abstract}

Keywords: E-readiness, E-planning, Mamberamo Tengah District

\section{ABSTRAK}

$P^{c}$ enelitian ini bertujuan untuk mengukur E-Readiness Kabupaten Mamberamo Tengah Dalam Penerapan E-Planning. Kabupaten Mamberamo Tengah secara geografis termasuk daerah yang memiliki keterbatasan akses, namun Di sisi lain harus melakukan inovasi yang tidak biasa untuk mengejar ketertinggalan dari daerah lainnya. Penelitian ini akan membahas eksisting kondisi serta syarat-syarat apa saja yang harus disiapkan oleh Kabupaten Mamberamo Tengah untuk menerapkan pelaksanaan perencanaan berbasis elektronik.

Penelitian ini menggunakan penelitian kualitatif. Metode yang digunakan dalam mengukur e-readiness yaitu metode e-readiness yang dikembangkan dari model hubungan variabel e-readiness menurut Musa (2010). Indikator-indikator yang diintegrasikan ke dalam kerangka pengukuran e-readiness dalam tool dipetakan ke dalam tiga faktor penting yang memengaruhi 
e-readiness yaitu faktor teknologi, faktor manusia dan faktor institusional khususnya di tingkat lokal (pemerintah daerah).

Hasil pengukuran e-readiness menunjukkan bahwa pemerintah Kabupaten Mamberamo Tengah belum siap dalam menerapkan e-planning baik diukur dari faktor teknologi, faktor manusia maupun faktor institusional, sehingga ini menjadi perhatian khusus bagi pemerintah daerah agar lebih serius dalam mempersiapkan pembangunan infrastruktur dan juga pemerintah daerah perlu membangun kerja sama antarpemerintah, pihak swasta dan juga masyarakat serta perlu adanya regulasi yang secara khusus berbicara tentang Sistem Informasi Perencanaan Daerah (SIPD) agar lebih baik ke depannya dan pelaksanaan e-planning dapat berjalan sesuai dengan peraturan yang berlaku secara efektif dan efisien.

Kata kunci: E-readiness, E-planning, Kabupaten Mamberamo Tengah

\section{PENDAHULUAN}

Pemerintah Indonesia saat ini sedang mengimplementasikan sistem e-government, sesuai dengan Instruksi Presiden No. 3 Tahun 2003 tentang Kebijakan dan strategi Nasional Pengembangan E-Government. Di mana sistem e-government ini menggunakan kemajuan teknologi dan komunikasi, yang pada dasarnya penerapan e-government ini adalah untuk meningkatkan kualitas proses pelayanan dari lembaga pemerintah kepada masyarakat melalui pelayanan secara online. Implementasi e-government ini juga memudahkan pemerintah dalam menyinkronkan data dari pusat hingga daerah serta melalui sistem ini masyarakat dapat berpartisipasi langsung dan juga mengontrol pekerjaan pemerintah.

Pelaksanaan e-planning di Indonesia saat ini sangat membantu dalam perencanaan pembangunan daerah, karena dalam penerapan e-planning ini sangat membantu dan mempermudah pemerintah dalam menyinkronkan data perencanaan pembangunan dari tingkat pusat, selanjutnya daerah provinsi kabupaten/kota. Pelaksanaan e-planning di beberapa daerah memiliki keterbatasan dalam penerapannya ditinjau dari beberapa faktor yaitu sumber daya manusia, sarana dan prasarana, komitmen pemangku kebijakan, dan sistem informasi dari e-planning itu sendiri (Sani, Balgi, 2017).

Penerapan e-government di setiap daerah memiliki kendala dan masalahnya masing-masing oleh karena itu perlu adanya $e$-readiness dalam mengukur kesiapan suatu daerah. Berdasarkan berbagai penelitian menyatakan bahwa kesiapan suatu daerah dalam menerapkan e-government memiliki masalahnya masing-masing tergantung situasi, kondisi dan juga letak geografis. Adapun masalah yang dihadapi sekarang adalah sebagai berikut. 1) Analisis Kesiapan Kota Cerdas; 2) Model E-Readiness untuk Pengukuran Kesiapan Pemerintah Daerah dalam Penerapan Smart Government Studi Kasus Pemerintah Provinsi Gorontalo; 3) E-Readiness Provinsi Kepulauan Riau dalam Penerapan E-Government (Studi terhadap Kepri Smart Province); dan 4) Kajian Teoretis: Model E-Government Readiness Pemerintah Kabupaten/Kota dan Keberhasilan E-Government. Penelitianpenelitian ini menunjukkan beberapa faktor yang memengaruhi e-readiness di setiap daerah di antaranya:

a) Kesiapan masyarakat, karena partisipasi dan kepercayaan masyarakat serta penguasaan Pendidikan dan Kompetensi Teknologi Informasi dan Komunikasi (TIK) sangat penting dalam penerapan E-Government;

b) Faktor teknologi, ini juga ikut memengaruhi karena ketersediaan, kehandalan, ketercakupan internet serta anggaran sangat menunjang untuk keberhasilan dalam penerapan E-Government. serta; 
c) Faktor kelembagaan, di mana kebijakan anggaran, kebijakan program dan instrumen hukum sangat berpengaruh terhadap kelancaran suatu kebijakan sistem E-Government.

Kabupaten Mamberamo Tengah merupakan Daerah Otonomi Baru yang sulit dijangkau, maka perlu mempersiapkan segala perencanaan pembangunan guna mengembangkan infrastruktur di daerah. Perencanaan Pembangunan di daerah Kabupaten Mamberamo Tengah berdasarkan Permendagri No. 86 Tahun 2017 tentang Tata Cara Perencanaan, Pengendalian dan Evaluasi Pembangunan Daerah tentang Rencana Pembangunan Jangka Panjang Daerah dan Rencana Jangka Menengah Daerah serta tata cara Perubahan Rencana Pembangunan Jangka Panjang Daerah, Rencana Pembangunan Jangka Menengah Daerah, dan Rencana Kerja Pemerintah Daerah. Pada Pasal 14 menyebutkan bahwa penyusunan RPJPD, RPJMD, dan RKPD dilakukan berbasis e-planning. Dengan ini maka pemerintah perlu menggunakan metode e-readiness dalam mengukur kesiapan Pemerintah Kabupaten Mamberamo Tengah dalam menjalankan perencanaan pembangunan daerah karena terkait dengan pelaksanaan e-government ini membutuhkan kesiapan dari berbagai faktor untuk menunjang terwujudnya e-planning.

Dengan kondisi geografis yang sulit, penggunaan teknologi informasi dan komunikasi dalam penyelenggaraan pemerintahan menjadi kebutuhan yang tidak bisa dihindarkan. Penerapan e-government di daerah terisolir justru dapat meningkatkan kinerja karena Teknologi Informasi dan Komunikasi (TIK) akan membangun komunikasi dengan daerah lainnya dengan lebih mudah, cepat dan tepat.

$$
\begin{aligned}
& \text { Kabupaten Mamberamo Tengah } \\
& \text { termasuk daerah yang memiliki } \\
& \text { katerbatasan akses, namun Di sisi lain harus } \\
& \text { melakukan inovasi yang tidak biasa untuk } \\
& \text { mengejar ketertinggalan dari daerah lainnya. }
\end{aligned}
$$

Penelitian ini ditunjukkan untuk melihat kesiapan Kabupaten Mamberamo Tengah, di dalam istilah akademis disebutkan sebagai e-readiness dalam penerapan e-planning. Penelitian ini akan membahas eksisting kondisi serta syarat-syarat apa saja yang harus disiapkan oleh Kabupaten Mamberamo Tengah untuk menerapkan pelaksanaan perencanaan berbasis elektronik.

\section{Identifikasi Masalah}

Adapun identifikasi masalah berdasarkan uraian dari latar belakang di atas, maka dapat dirumuskan identifikasi masalah sebagai berikut.

1. Kabupaten Mamberamo Tengah merupakan daerah otonom baru, di mana masih perlu mempersiapkan perencanaan pembangunan dan infrastruktur;

2. Pemerintah daerah Kabupaten Mamberamo Tengah memiliki keterbatasan akses infrastruktur, dan

3. Pemerintah Kabupaten Mamberamo Tengah memiliki keinginan untuk melakukan inovasi dalam penyelenggaraan pemerintahan dengan menerapkan perencanaan berbasis elektronik/e-planning.

\section{Maksud dan Tujuan Penelitian}

Penelitian ini dimaksudkan untuk memperoleh gambaran mengenai e-readiness Kabupaten Mamberamo Tengah dalam penerapan e-planning. Sementara itu, berdasarkan latar belakang dan permasalahan yang terjadi, maka tujuan dari penelitian ini adalah untuk melihat e-readiness Kabupaten Mamberamo Tengah dalam penerapan e-planning. Kabupaten Mamberamo Tengah ini merupakan daerah otonom baru yang berada di daerah Pegunungan Tengah di mana akses ke daerah ini cukup sulit, sehingga perlu adanya e-readiness infrastruktur pemerintahan secara efektif dan efisien. 


\section{TEORI YANG DIGUNAKAN}

Pengembangan

e-government menyimpan potensi yang sangat besar, potensi ini harus mampu membawa semangat bagi pemerintah daerah untuk mentransformasikannya menjadi sebuah program penting yang mendukung reformasiadministrasi, sosial, dan ekonomi, yang kesemuanya itu berorientasi pada memfasilitasi faktor-faktor keberhasilan e-government itu sendiri, dan terlebih lagi untuk memaksimalkan manfaat yang dapat diambil masyarakat dari transformasi e-government yang dilakukan (Musa, 2010).

Dalam upaya menghindari atau setidaknya meminimalisir kegagalan tersebut, penerapan e-government harus dimulai dengan membentuk kesiapan diri suatu organisasi, yang mana tingkat kesiapan tersebut ditunjukkan dari hasil pengukuran e-readiness. Selanjutnya, efektivitas hasil pengukuran e-readiness ditentukan oleh seberapa efektif suatu organisasi mengidentifikasi persoalan-persoalan yang ada di lingkungannya, menetapkan faktor dan indikator e-readiness yang relevan. Untuk itu, mempelajari situasi yang berkembang di tingkat nasional dan regional menjadi faktor penting dalam penetapan indikator dan faktor-faktor terkait.

Kesiapan Elektronik (E-Readiness) merupakan kesiapan mental atau fisik suatu organisasi untuk suatu pengalaman atau tindakan e-learning (Priyanto,2008). E-Readiness juga diartikan tingkat di mana masyarakat diarsipkan untuk partisipasi dalam teknologi yang dapat membantu untuk membangun menuju masyarakat yang lebih baik (Waryanto, 2010). E-Readiness merupakan tingkat di mana masyarakat siap untuk mendapatkan keuntungan yang bisa didapatkan melalui teknologi informasi dan komunikasi.

Menurut Penulis e-readiness merupakan suatu metode yang digunakan untuk mengukur kesiapan pemerintah daerah dalam menerapkan e-government dan internet merupakan fasilitator utama dalam menunjang keberhasilan kebijakan. E-readiness sangat membantu pemerintah dalam mengukur kesiapan daerah agar pemerintah akan lebih terarah dalam perencanaan pembangunan menuju pada good governance.

Penetapan indikator dan faktorfaktor e-readiness yang relevan akan mengarahkan pada adaptasi sebuah model atau tool e-readiness yang sesuai untuk konteks atau regional daerah tertentu. Tool ini harus sederhana dan mudah untuk digunakan dan konsisten dengan realitas lingkungan pemerintahan tertentu. Tool ini harus mengukur beberapa aspek yang dipandang penting bagi suatu daerah di mana e-government tersebut akan diterapkan, yang mana kondisi yang dihadapi oleh setiap daerah berbeda satu sama lainnya.

Tool tersebut mengukur aspek-aspek tertentu dari masyarakat dan beberapa fitur layanan dan teknologi yang diperlukan dalam transformasi penyelenggaraan pemerintahan dan sistem konvensioanal ke arah digital. Pada dasarnya tool ini dimaksudkan untuk memberikan indikasi terbaik tentang variabel yang memengaruhi e-government sehingga hasil pengukuran tersebut dapat membantu pengambilan keputusan dalam menentukan apa saja yang patut menjadi prioritas dan perbaikan apa yang kruisial harus dilakukan dalam meningkatkan e-readiness dari suatu kabupaten.

Berdasarkan analisis ini maka Musa menetapkan sejumlah indikator yang diusulkan sebagai instrumen pengukuran e-readiness di tingkat pemerintah daerah dan dapat dikembangkan untuk pemerintah daerah negara-negara berkembang lainnya. Indikator-indikator tersebut dipetakan ke dalam tiga faktor penting yang memengaruhi $e$-readiness, yaitu sebagai berikut. 


\begin{tabular}{|c|c|c|}
\hline Faktor Teknologi & Faktor Manusia & Faktor Institusioanl \\
\hline $\begin{array}{ll}\text { - } & \text { Ketersediaan (availability) } \\
\text { - } & \text { Kehandalan (Reliability) } \\
\text { - } & \text { Penetrasi internet } \\
\text { (ketercakupan) } \\
\text { - } \text { Biaya }\end{array}$ & $\begin{array}{ll}\text { - } & \text { Kepercayaan terhadap } \\
\text { - } & \text { Pemerintah } \\
\text { - } & \text { Pendidikikan } \\
\text { - } & \text { Kompetensi TIK }\end{array}$ & $\begin{array}{ll}\text { - } & \text { Online service } \\
\text { - } & \text { Integrasi } \\
\text { - } & \text { Willingness (political will) } \\
\text { - } & \text { Kebijakan anggaran } \\
\text { - } & \text { Kebijakan program } \\
\text { - } & \text { Instrumen hukum } \\
\end{array}$ \\
\hline
\end{tabular}

Sumber: Model hubungan variabel e-readiness (Musa,2010)

\section{METODE PENELITIAN}

\section{Desain Penelitian}

Penelitian ini dilakukan dengan metode kualitatif dengan pendekatan deskriptif. Pada tahapan desain penelitiane-readiness penerapan e-planning menggunakan model hubungan variabel e-readiness dari Musa (2010). Dalam upaya menyiapkan penerapan e-government harus dimulai dengan membentuk kesiapan harus diri dari suatu kabupaten yang mana tingkat kesiapan tersebut dapat dilihat dari hasil pengukuran $e$-readiness.

\section{Data yang Diperlukan}

Untuk mempermudah mengidentifikasi sumber data, maka perlu diklasifikasikan menjadi tiga bagian yaitu sebagai berikut.

1. Manusia, yaitu mereka yang terlibat dan melibatkan diri dalam proses kegiatan dalam hal ini peneliti melakukan wawancara bersama informan;

2. Sumber Data Tertulis, berupa buku atau dokumen, arsip-arsip dan surat-surat penting yang berhubungan dengan penelitian;

3. Data tidak tertulis yaitu kata-kaya atau tindakan yang terjadi saat melakukan penelitian yang berkaitan dengan penelitian.

Berdasarkan sumbernya, data penelitian dapat dikelompokkan dalam dua jenis yaitu

1. Data Primer

Data primer adalah data yang diperoleh oleh peneliti secara langsung dari sumber datanya. Teknik yang dapat digunakan peneliti untuk mengumpulkan data primer melalui wawancara dan observasi.

2. Data Sekunder

Data sekunder adalah data yang diperoleh peneliti dari berbagai sumber yang telah ada (peneliti sebagai tangan kedua). Data sekunder dapat berupa buku seperti Mamberamo Tengah Dalam Angka, Indeks Kepuasan Masyarakat, arsip seperti surat Rencana Aksi KPK, Keputusan Bupati dan juga Peraturan Daerah serta ada juga dokumen pribadi seperti foto-foto wawancara dan juga sarana dan prasarana kantor yang memengaruhi e-readiness penerapan e-planning di Bappeda.

\section{Teknik dan Instrumen Pengumpulan Data}

Pengumpulan data adalah prosedur yang sistematis dan standar untuk memperoleh data yang diperlukan. Teknik pengumpulan data yang digunakan peneliti dalam penelitian ini:

\section{Wawancara}

Peneliti langsung turun lapangan untuk mengamati perilaku dan aktivitas di lokasi penelitian untuk mendapatkan gambaran secara menyeluruh. Peneliti melakukan dengan berhadapan dengan informan. Wawancara dilakukan untuk mendapat informasi mengenai $e$-readiness dalam penerapan e-planning, apa sajakah faktor-faktor pendukung dan penghambat serta upaya yang 
dilakukan dalam e-readiness Kabupaten Mamberamo Tengah dalam penerapan e-planning.

2. Observasi

Peneliti langsung turun ke lapangan untuk mengamati perilaku dan aktivitas individu-individu di lokasi penelitian untuk mendapat gambaran secara menyeluruh tentang penyaksian terhadap seluruh peristiwa-peristiwa kemudian dilanjutkan dengan membuat pemetaan sehingga dapat menggambarkan sasaran yang diteliti yaitu faktor-faktor yang memengaruhi serta upaya yang dilakukan dalam $e$-readiness dalam penerapan $e$-planning di Kabupaten Mamberamo Tengah.

3. Dokumentasi

Dokumentasi berupa fasilitas pelayanan kantor seperti genset, solarsel, jaringan wifi (internet) dokumen publik, seperti laporan kemajuan pelaksanaan e-planning di Mamberamo Tengah dari tahun 2017, 2018 dan 2019, dan juga termasuk di dalamnya ada peraturan daerah yang berkaitan dengan fokus dalam penelitian.

\section{HASIL PENELITIAN DAN PEMBAHASAN}

\section{E-Readiness Kabupaten Mamberamo Tengah dalam Penerapan E-Planning}

Pengumpulan data untuk penelitian ini dilakukan terhadap tiga faktor yang terkait dalam e-readiness penerapan e-planning di Kabupaten Mamberamo Tengah Provinsi Papua yaitu faktor teknologi, manusia, dan institusional. Berdasarkan hasil penelitian dapat dijelaskan sebagai berikut.

1. Faktor Teknologi

Faktor teknologi sangat memengaruhi e-readiness karena ketersediaan, kehandalan, ketercakupan internet serta anggaran sangat menunjang untuk keberhasilan dalam penerapan e-planning di Kabupaten Mamberamo Tengah. Ketersediaan sarana dan prasarana baik jaringan internet, komputer, genset serta solarsel sudah tersedia tetapi belum berjalan secara efektif dan efisien karena sering mengalami gangguan jaringan dan juga pasokan bahan bakar minyak (BBM) terbatas, sehingga masih banyak yang harus disiapkan dan tingkatkan agar pelayanan dapat berjalan secara efektif dan efisien.

2. Faktor Manusia

Faktor manusia juga sangat memengaruhi e-readiness karena ketersediaan, kehandalan, ketercakupan internet serta anggaran sangat menunjang untuk keberhasilan dalam penerapan e-planning di Kabupaten Mamberamo Tengah. Pemerintah daerah secara bertahap mempersiapkan pegawai dalam pengembangan potensi serta keterampilan pegawai dalam pendidikan formal maupun nonformal. Secara khusus pegawai disiapkan dan diikutsertakan dalam pelatihan teknik informasi dan komunikasi untuk meningkatkan potensi pegawai dalam menggunakan komputer dan juga mengelolah sistem aplikasi.

3. Faktor Konstitusional

Faktor konstitusional sangat memengaruhi e-readiness karena kebijakan anggaran, kebijakan program dan instrumen hukum sangat berpengaruh terhadap kelancaran serta keberhasilan penerapan e-planning di Kabupaten Mamberamo Tengah. Penerapan e-planning belum memiliki regulasi daerah yang mengatur tentang SIPD karena pelaksanaan e-planning di Kabupaten Mamberamo Tengah berdasarkan Rencana Aksi KPK yang tertuang dalam Keputusan Bupati Mamberamo Tengah No. 31 Tahun 2017 tentang Rencana Aksi Pencegahan 
Korupsi Terintegrasi Pemerintah Kabupaten Mamberamo Tengah 2017-2018. Pelayanan di Kabupaten Mamberamo Tengah masih secara offline, dan data perencanaan daerah belum terintegrasi dari tiap-tiap OPD terutama e-planning dan e-budgeting. Untuk kebijakan program dan kebijakan anggaran e-readiness penerapan e-planning telah dianggarkan dalam APBD 2017, 2018 dan 2019.

\section{Faktor Penghambat dan Faktor Pendukung yang Memengaruhi E-Readiness dalam Penerapan E-Planning di Kabupaten Mamberamo Tengah}

E-Planning pada dasarnya memanfaatkan teknologi informasi dalam mengakses internet sebagai alat untuk membantu menjalankan sistem aplikasi pemerintahan secara efektif, efisien, transparan serta terintegrasi dari tingkat kampung, distrik hingga kabupaten. E-Readiness Kabupaten Mamberamo Tengah dalam penerapan e-planning, memiliki faktorfaktor pendukung dan juga faktor-faktor penghambat dalam penerapannya sehingga tidak berjalan secara efektif dan efisien. Adapun faktor-faktor pendukung dalam e-readiness Kabupaten Mamberamo Tengah dalam penerapan e-planning antara lain:

1. Pemerintah daerah merespons secara positif penerapan e-planning di Bappeda dengan menganggarkan dalam APBD tahun 2017, 2018 dan 2019 berdasarkan Keputusan Bupati Mamberamo Tengah No. 31 Tahun 2017 tentang Rencana Aksi Pencegahan Korupsi Terintegrasi Kabupaten Mamberamo Tengah Tahun 2017-2018;

2. Pemerintah daerah membangun infrastruktur teknologi dalam hal ini jaringan internet dengan kapasitas 4 Mbps khusus untuk Bappeda dan menggunakan genset serta solarsel sebagai sumber listrik;
3. Bappeda juga mempersiapkan setiap pegawai untuk mengikuti pendidikan formal maupun nonformal untuk meningkatkan potensi pegawai;

Adapun faktor-faktor penghambat dalam e-readiness Kabupaten Mamberamo Tengah dalam penerapan e-planning antara lain sebagai berikut.

1. Belum adanya regulasi sebagai payung hukum dari pemerintah daerah dalam penerapan e-government secara khusus e-planning. Regulasi sangat penting dalam menjelaskan secara rinci mengenai mekanisme penerapan e-government karena perlu adanya kebijakan e-government terpadu yang disesuaikan dengan kebutuhan masingmasing daerah;

2. E-Readiness penerapan e-planning belum maksimal karena rendahnya kualitas sumber daya manusia dalam mengelolah dan mempersiapkan penerapan e-planning serta terbatasnya tenaga ahli yang kompeten di bidang teknik informatika;

3. Belum terintegrasinya data antarinstansi pemerintahan dari tingkat kampung, distrik hingga kabupaten;

4. Belum adanya pembangkit listrik di Kabupaten Mamberamo Tengah, sehingga tiap instansi menggunakan gensetatau solarsel dalam melaksanakan tugas dan tanggung jawab tiap instansi .

5. Perlu adanya forum rutin antarinstansi pemerintahan khususnya pegawai di lingkungan Kabupaten Mamberamo Tengah tentang pentingnya e-readiness penerapan e-planning.

\section{Upaya yang Dilakukan Pemerintah Kabupaten Mamberamo Tengah dalam Penerapan E-Readiness Penerapan E-Planning}

Upaya-upaya pemerintah dalam e-readiness Kabupaten Mamberamo Tengah 
dalam penerapan e-planning adalah sebagai berikut.

1. Membuat Regulasi atau payung hukum yang mengatur secara khusus tentang Sistem Informasi Perencanaan Daerah (SIPD);

2. Membangun kerja sama dengan Kemkominfo dalam pembangunan Palapa Ring di Gunung Mega yang berada di antara Kabupaten Mamberamo Tengah dan kabupaten Tolikara;

3. Membangun kerja sama dengan Kabupaten Jayawijaya dalam membangun sistem aplikasi e-planning di Bappeda Kabupaten Mamberamo Tengah;

4. Memberikan pendidikan formal dan nonformal bagi pegawai Bappeda dalam meningkatkan potensi pegawai;

5. Pemerintah daerah juga perlu melakukan pendidikan dan pelatihan SDM secara khusus di bidang teknologi informasi dan komunikasi yang terintegrasi dalam menunjang e-readiness penerapan e-planning.

6. Mengadakan sosialisasi atau forum secara rutin antarinstansi pemerintahan untuk membahas pengembangan e-government secara khusus e-planning di Kabupaten Mamberamo Tengah.

\section{SIMPULAN DAN SARAN}

\section{SIMPULAN}

Berdasarkan hasil penelitian dan pembahasan E-Readiness Kabupaten Mamberamo Tengah dalam penerapan E-Planning maka dapat disimpulkan sebagai berikut.

1. E-Readiness Kabupaten Mamberamo Tengah dalam penerapan e-planning dilihat dan diukur dari tiga faktor yaitu faktor teknologi, faktor manusia dan faktor institusional. Dari ketiga faktor ini dapat disimpulkan bahwa
Kabupaten Mamberamo Tengah belum siap menerapkan e-planning karena pemerintah daerah masih perlu dan masih banyak yang harus dipersiapkan baik dari segi teknologi, manusia maupun institusional agar dapat menerapkan e-planning secara efektif, efisien, transparan dan juga terintegrasi.

2. Adanya faktor pendukung dan juga faktor penghambat dalam e-readiness Kabupaten Mamberamo Tengah dalam penerapan e-planning. Faktor pendukung yaitu

a. Pemerintah daerah merespons baik aksi KPK mengenai penerapan e-planning di Kabupaten Mamberamo Tengah dengan menganggarkan dalam APBD Bappeda tahun 2017, 2018 dan 2019;

b. Pengadaan Jaringan Internet yaitu wifi dengan kapasitas 4 Mbps;

c. Bappeda mempersiapkan setiap pegawai untuk mengikuti pendidikan formal maupun nonformal dalam rangka peningkatan potensi pegawai.

3. Faktor penghambat dari e-readiness Kabupaten Mamberamo Tengah dalam penerapan e-planning yaitu

a. Belum adanya regulasi sebagai payung hukum dari pemerintah daerah dalam penerapan e-government secara khusus e-planning;

b. Rendahnya kualitas atau potensi Sumber Daya Manusia dalam mengelolah dan mempersiapkan penerapan e-planning serta terbatasnya tenaga ahli yang kompeten di bidang teknik informatika;

c. Belum adanya pembangkit listrik di Kabupaten Mamberamo Tengah, sehingga di Kabupaten Mamberamo 
Tengah menggunakan genset dan juga solarsel sebagai sumber listrik;

d. Belum terintegrasinya data antarinstansi pemerintahan dari tingkat kampung, distrik hingga instansi di kabupaten;

e. Belum adanya forum rutin antarinstansi dan juga sosialisasi kepada masyarakat tentang pelaksanaan e-planning di lingkungan Kabupaten Mamberamo Tengah.

3. Upaya yang dilakukan pemerintah Kabupaten Mamberamo Tengah dalam penerapan e-planning antara lain:

a. Membangun kerja sama dengan Kemkominfo dalam pembangunan Palapa Ring di Gunung Mega yang berada di antara Kabupaten Mamberamo Tengah dan Kabupaten Tolikara;

b. Membangun kerja sama dengan Kabupaten Jayawijaya dalam mempersiapkan sistem aplikasi e-planning;

c. Memberikan pendidikan formal maupun nonformal bagi pegawai Bappeda dalam rangka meningkatkan potensi pegawai.

\section{SARAN}

Berdasarkan hasil penelitian di atas, maka peneliti juga mengemukakan saran sebagai berikut.

1. Perlu adanya perhatian khusus dari pemerintah daerah untuk e-readiness Kabupaten Mamberamo Tengah dalam penerapan e-planning;

2. Perlu adanya Peraturan Daerah sebagai payung hukum yang secara khusus berbicara tentang Sistem Informasi Perencanaan Daerah (SIPD) agar pelaksanaan e-planning di Bappeda Mamberamo Tengah dapat berjalan sesuai dengan peraturan yang berlaku dan secara efektif dan efisien;
3. Perlu adanya kerja sama dari semua pihak antara pemerintah, swasta dan juga masyarakat untuk e-readiness Kabupaten Mamberamo Tengah dalam Penerapan e-planning.

4. Perlu adanya forum rutin antarinstansi pemerintahan dan juga sosialisasi kepada masyarakat di lingkungan Kabupaten Mamberamo Tengah tentang e-readiness penerapan e-government secara khusus e-planning.

\section{KAJIAN PUSTAKA}

Creswell, John. 2014. Research Design (Pendekatan Kualitatif, Kuantitatif, dan Mixed. Pustaka Pelajar. Yogyakarta.

Departemen Pendidikan dan Kebudayaan, Kamus Besar Bahasa Indonesia, (Jakarta: Balai Pustaka, 1988).

Effendy, Khasan. 2010. Memadukan Metode Kuantitatif Kualitatif. Indra Prahasta.

Hamdi, Muchlis. 2015. kebijakan publik, Proses, Analisis, dan Partisipasi. Bogor: Ghalia Indonesia

Indrayani Etin, 2015. E-Government, Konsep, implementasi dan Perkembangan di Indonesia.

Nazir.Moh. 2014. Metode Penelitian. Ghalia Indonesia. Bogor.

Silalahi, Ulber. 2012. Metodologi Penelitian Sosial. Refika Aditama. Bandung.

Sumaryadi, 2006. Otonomi Daerah Khusus dan Birokrasi Pemerintahan

Sumanto Teori dan Aplikasi Metode Penelitian. Center of Academic Publishing Service (CAPS). Yogyakarta. 2014.

Patarai Idris, 2015. Desentralisasi Pemerintahan Dalam Perspektif Pembangunan Politik di Indonesia. De la macca. Makassar.

\section{Peraturan Perundang-Undangan}

Undang-Undang Republik Indonesia No. 25 Tahun 2004 tentang Sistem Perencanaan Nasional.

Undang-Undang No. 23 Tahun 2014 tentang Pemerintahan Daerah. 
Peraturan Pemerintah No. 18 Tahun 2016 tentang Perangkat Daerah.

Instruksi Presiden Republik Indonesia No. 3 Tahun 2003 tentang Kebijakan dan Strategi Nasional Pengembangan E-Government.

Permen No. 86 Tahun 2017 tentang Tata Cara Perencanaan Pengendalian dan Evaluasi Pembangunan Daerah, Tata Cara Evaluasi Rancangan Peraturan Daerah tentang Rencana Pembangunan Jangka Menengah Daerah, serta Tata Cara Perubahan Rencana Pembangunan Jangka Panjang Daerah, Rencana Pembangunan Jangka Menengah Daerah, dan Rencana Kerja Pemerintah Daerah.

Peraturan Daerah Provinsi Papua No. 19 Tahun 2016 tentang Pembentukan dan Susunan Perangkat Daerah.

Peraturan Bupati Mamberamo Tengah No. 29 Tahun 2016 tentang Struktur Organisasi dan Tata Kerja Badan Perencanaan Pembangunan Daerah.

Keputusan Bupati Mamberamo Tengah No. 31 Tahun 2017 tentang Rencana Aksi Pencegahan Korupsi Terintegrasi Pemerintah Kabupaten Mamberamo Tengah tahun 2017-2018.

\section{Jurnal}

Vikram Singh, Subhash Chander, Sunil Kumar, 2009, Impact of E-Governance Among Rural \& Urban Areas of Punjab, conference Paper.

Dugdale, Daly, Papandrea, Maley, 2005, Accessing e-government: challenges for citizens and organizations, International Review of Administrative Sciences.

\section{Website}

http: //lestarinurbudi.wordpress. com/2016/03/29/pengertian-danpenjelasan-e-government/.

http: //www.jmc.co.id/blog/detail/E-PlanningMemudahkan-Kinerja-BAPPEDA-diSeluruh-Indonesia.

http: //www.bangda.kemendagri.go.id/ berita / b a c a _kontent/1077/ penerapan_aplikasi_e-planning_dalam_ perencanaan_pembangunan_daerah_ dan_simda_sebagai_alternatif_aplikasi_ penilaian_kinerja_instansi_pemerintah_ daerah.

http: //www.jmc.co.id/blog/detail/E-PlanningMemudahkan-Kinerja-BAPPEDA-diSeluruh-Indonesia. 